\title{
Alternatively: New Approach to Incorporating Intercultural Content in EFL Instructor Development in Thailand
}

\author{
Kanlaya Promwatcharanon \\ Chiang Mai Rajabhat University \\ Thailand
}

\begin{abstract}
One of the goals of English language training programs is to educate learners to become intercultural speakers; those who can deal with linguistic and cultural complexity, when taking part in multicultural situations. Hence, the participating trainee students, who enrolled in the "Methods of Teaching" course at Chiang Mai Rajabhat University in Thailand, were asked to train and to integrate the intercultural contents with the multifunctional instructional method, the 4MAT approach. This new practice challenged the participants to think creatively by using various activities or techniques to teach the language, and to develop their abilities by incorporating intercultural content in their teaching practices. In this study, the Intercultural Communicative Language Teaching (ICLT) model, as well as associated ICLT tests and questionnaires were employed to gather data, which revealed the findings that trainee students' ICLT competence were improved (98.46\%) and their attitudes towards ICLT was positive high (4.77 out of 5).
\end{abstract}

\section{Introduction}

In the current context of globalization, the issue of delivering intercultural communicative competence (ICC) to "English as a Foreign Language" (EFL) learners has been identified as one of the ultimate goals in the field of English language education (e.g., [2]; [5]; [7]). Moreover, English language education should equip learners with the knowledge of intercultural communication and the ability to use it effectively to bridge cultural differences and to achieve more harmonious and productive relationships [18].

In the ASEAN context, and as a member of the ASEAN community since 2015, learners in Thailand have been experiencing the impact of the Southeast Asian revolution in terms of diversity and crosscultural knowledge, life styles, mainstream social values and economic transformations [17]. Thus, it is recommended to incorporate English content that are used in ASEAN countries and to develop programs with emphasis on intercultural language education in order to link learners to the ASEAN community, and consequently to develop ICC.

It is therefore critical to familiarize learners with cultural differences in order to help them become inter culturally aware, of their own culture and the presence of others, as well as to appreciate and respect the diversity and differences between various cultures [17]. However, most instructors have limited knowledge regarding intercultural communication [20]. Consequently, teachers in different classrooms in various parts of the world still ignore the importance of teaching culture as a part of learning a language. [9]. That means that teachers attempt to promote and focus on language proficiency, since they lack of adequate training on how to incorporate culture in to their teaching practices. Furthermore, the lack of intercultural content results in ignoring important elements of diverse culture within the ASEAN community in terms of visible or tangible cultural content (e.g. food, costumes, places, artifacts), as well as invisible or intangible cultural content (e.g. values, attitudes, norms and behaviors).

Concerning this matter, the researcher, who is also a lecturer of the English Education program, found that customized training programs should be embedded to provide trainee students with the knowledge to become competent instructors by nurturing them in order to gain essential skills and to be equipped the necessary knowledge to be in innovative in their classrooms, whilst using the ICLT model, the ASEAN content, which was integrated into 8 steps of the 4MAT method, were developed to facilitate the development of trainees' ICC and their English teaching abilities. Following two research questions were formed:

1) What are EFL trainee students' attitudes towards intercultural communicative language teaching (ICLT)?

2) To what extent is EFL trainee students' intercultural communicative competence (ICC) 
enhanced after participating in the intercultural communicative language teaching course?

\section{Methodology}

\subsection{Course Design}

The intercultural communicative language teaching (ICLT) model was offered as part of the English Education Program at Chiang Mai Rajabhat University under the course titled CI 4642: "Methods of Teaching English", lasting over a period of 10 weeks. The ICLT was taught by a Thai English Instructor (the researcher), who met with the class 3 hours weekly for a total of 30 hours. The thirty-hour model was divided into two parts. The first part contained the lessons and coaching by the researcher, ( 9 hours of the teaching time) and a group teaching (18 hours of teaching time), and the second part pertained to the end-of course assessment ( 3 hours of teaching time).

\subsection{Course Design: An Instructional Model}

Additional elements of intercultural content were integrated into the 3-unit English lesson titled "A 4MAT Approach Integration with ASEAN Social and Cultural Links" (ASCL). ASCL content consists of 3 units: Unit 1 "Welcome to the ASEAN Community," focusing on the background and national symbols of each member country (flags, currencies, clothes, flowers, and greetings). Unit 2 "Travel through the ASEAN Community", includes information about places to eat and visit around the ASEAN community. Unit 3 "Cultural Wonders", provides content about travel tips, and do's and don'ts, when traveling around the ASEAN community.

The participants were instructed using the ICLT model and the 4MAT Approach. This method improved learning achievement by sharing knowledge through an inquiry method, along with knowledge creation during interactive learning. Moreover, it helped developing knowledge presentation, and knowledge aesthetics, and reflective thinking. This method is well-known for its child-centered approach. There are 8-steps to the 4MAT Approach [13], namely:

Step 1: Creating experience

Step 2: Analyzing experience

Step 3: Integration of reflection into concept

Step 4: Developing theories and concepts

Step 5: Working on defined concepts

Step 6: Messing around

Step 7: Analyzing the usefulness of the application

Step 8: Doing it themselves and sharing what they do with others
Both the ASLC content and the 4MAT Approach were integrated into the teaching model for the research participants in the group teaching practices in order to train them to create the group lesson plans, to develop teaching materials and to prepare them for group teaching in the classroom; and most importantly, to encourage their ICC and attitudes towards ICLT.

\subsection{Participants}

The participants were sixty-two EFL trainee students in their fourth-year students of the English Education Program, who studied in the subject course CI 4642 "Methods of Teaching English" at Chiang Mai Rajabhat University, Thailand. Most of the participants, approximately $80 \%$, had opinion, awareness and basic knowledge of ASEAN studies. However, only $20 \%$ were able to correctly answer questions relating to the ASEAN community's history. This indicated a general lack of knowledge about intercultural communicative competence. The researcher divided the participants into 4 groups with 4 separated group lesson plans, namely Group 1: "Welcome to the ASEAN Community", Group 2: "Travel to See around the ASEAN Community", Group 3: "Travel to Eat through the ASEAN Community", and Group 4: "Cultural Wonders". The participants in each group were asked to join the prearranged unit lessons and practices under the 8 steps of the 4MAT approach. Ultimately, each group had to make their own group lesson plans and to design creative teaching materials.

\subsection{Research Instruments}

This study utilized two research instruments; including; 1) A questionnaire for assessing students' attitude toward ICLT and ICC, and 2) the ICLT instructional model evaluation form to collect data. The questionnaire was employed to obtain information from learners regarding their attitudes towards ICLT and ICC development after the course. The questionnaire's content included 20 items designed with a five-point scale (strongly disagree to strongly agree) which showed 4 of the IC elements, namely: intercultural knowledge, attitudes, awareness, and skills. The total reliability of the questionnaire, calculated by Cronbach, was 0.84 . The ICLT model was designed regarding lessons and approach to teaching with team teaching by student trainees addressing two issues attitudes towards ICLT and their ICC development. The ICLT evaluation form was used to collect data regarding trainees' language teaching competence and from the assessment made on the instruction procedures form, following the use of the ICLT model in the classroom. The ICLT competence evaluation form included six elements with the total scores of 40 , 
namely; Warm-up activity (5), 3P (Presentation, Practice, Production) procedure (15), Using classroom language and class controlling (5), Using teaching materials (5), Child-centered approach (5), and Measurement and Evaluation (5).

\subsection{Procedures}

The data collection was conducted in three stages; before, during and after the implementation of the intercultural language teaching course. Before the class, 62 trainee students were required to do the pre-test including the ICC test. During the process of teaching with the ICLT model, the participants were required to make their group lesson plans, group teaching materials, as well as their group trial teacher's acting as team teaching instructors, while the others were students, and the researcher acted as a supervisor grading the ICLT competence scores. After the course, the participants were asked to do the post-test on the ICC questionnaire.

In terms of the data analysis, the statistical methods (descriptive statistics; means and standard deviation) were employed to quantitatively analyze the questionnaire. All research instruments were piloted before the primary study in order to increase the validity and reliability.

\section{Findings}

\subsection{ELF trainee students' attitudes towards intercultural communicative language teaching and their intercultural communicative competence}

With regard to the quantitative data collected from the questionnaire, it is evident from Table 1 that the mean score of the EFL trainee students' attitudes towards ICLT after a ten-week course was 4.77 (out of 5), which indicated that there was a significantly strong agreement in learners' perceptions of ICLT. Accordingly, this concluded that students felt the most positive about ICLT after their course, as student's attitudes towards ICLT had significantly improved.

Table 1. EFL trainee students' attitudes towards ICLT

\begin{tabular}{cccc}
\hline Items & $\mu$ & $\begin{array}{c}\sigma \\
(\mathrm{N}=62)\end{array}$ & $\begin{array}{c}\text { Level of } \\
\text { Satisfaction }\end{array}$ \\
\hline 20 items & 4.77 & 0.37 & $\begin{array}{c}\text { Strongly } \\
\text { agree }\end{array}$
\end{tabular}

More remarkably, trainee students were aware of the elements of the ICC (see table 2), which consists of knowledge, attitudes, awareness, and skills. That is why learners were certain that it was necessary and important for them to have knowledge of foreign cultures $(\mu=4.90, \sigma=0.29)$, to develop their curiosity, openness, and readiness to learn about foreign cultures $(\mu=4.72, \sigma=0.44)$, to raise their awareness of cultures $(\mu=4.90, \sigma=0.29)$, and to be instructed how to communicate with people from different countries effectively and appropriately $(\mu=$ $4.58, \sigma=0.49$ ).

Table 2. EFL trainee students' attitudes towards ICC

\begin{tabular}{|c|c|c|c|}
\hline $\begin{array}{c}\text { Items } \\
(\mathrm{N}=62)\end{array}$ & $\mu$ & $\sigma$ & $\begin{array}{c}\text { Level of } \\
\text { Satisfaction }\end{array}$ \\
\hline Knowledge & 4.90 & 0.29 & $\begin{array}{c}\text { Strongly } \\
\text { agree }\end{array}$ \\
\hline Attitudes & 4.72 & 0.44 & $\begin{array}{c}\text { Strongly } \\
\text { agree }\end{array}$ \\
\hline Awareness & 4.90 & 0.29 & $\begin{array}{c}\text { Strongly } \\
\text { agree }\end{array}$ \\
\hline Skills & 4.58 & 0.49 & $\begin{array}{c}\text { Strongly } \\
\text { agree }\end{array}$ \\
\hline Average & 4.77 & 0.37 & $\begin{array}{c}\text { Strongly } \\
\text { agree }\end{array}$ \\
\hline
\end{tabular}

Additionally, all four ICC elements indicate the same pattern of a high level of satisfaction agreement. However, these results also revealed that learners found intercultural knowledge and awareness were easier to improve on than their attitudes and skills.

\subsection{ELF trainee students' intercultural communicative language teaching competence}

After a ten-week course and using the ICLT model, there was a noticeable change in trainee students' ICLT development as it is evident in Table 3. The score of the EFL trainee students for ICLT competence was at 98.46 percentage, which indicated that the vast number of the learners believed in the importance, necessity and the integration role of foreign cultures. Furthermore, the findings indicate that students become aware of the ASEAN Social and Cultural Links (ASCL) with the multifunctional teaching method of A 4MAT Approach into English language education, and they were well aware of the ICC.

Most of the trainee students improved towards their essential competencies of the English language training program, which guided students to become intercultural speakers, who could deal with cultural complexity and were able to take part in multicultural situations. This denotes that EFL trainees' ICLT improved significantly after the tenweek course based on highest average score of a trial team teaching of 98.46 percentage. 
Table 3. EFL trainee students' ICLT competence

\begin{tabular}{lcc}
\hline \multicolumn{1}{c}{ Items/(N=62) } & $\begin{array}{c}\text { Total } \\
\text { Scores }\end{array}$ & Scores \\
\hline Warm-up (5) & 310 & 310 \\
3P teaching procedure (15) & 930 & 892 \\
Classroom language \& control (5) & 310 & 310 \\
Use of teaching aid (5) & 310 & 310 \\
Child-centered approach (5) & 310 & 310 \\
Measurement \& Evaluation (5) & 310 & 310 \\
\multicolumn{3}{c}{ Total } \\
\multicolumn{3}{c}{ Total Percentage $=98.46$} \\
\hline
\end{tabular}

During the ICLT course, all the trainee students had to work in groups to design the group lesson plans with teaching aids or materials created by the group according to each unit plan of the ICLT model or ASCL lessons (See figures 1-4). Not surprisingly, trainee students knew how to deal with culture and intercultural communication in the classroom, as they had adequate training on how to incorporate contents and learning methods into their teaching practices.

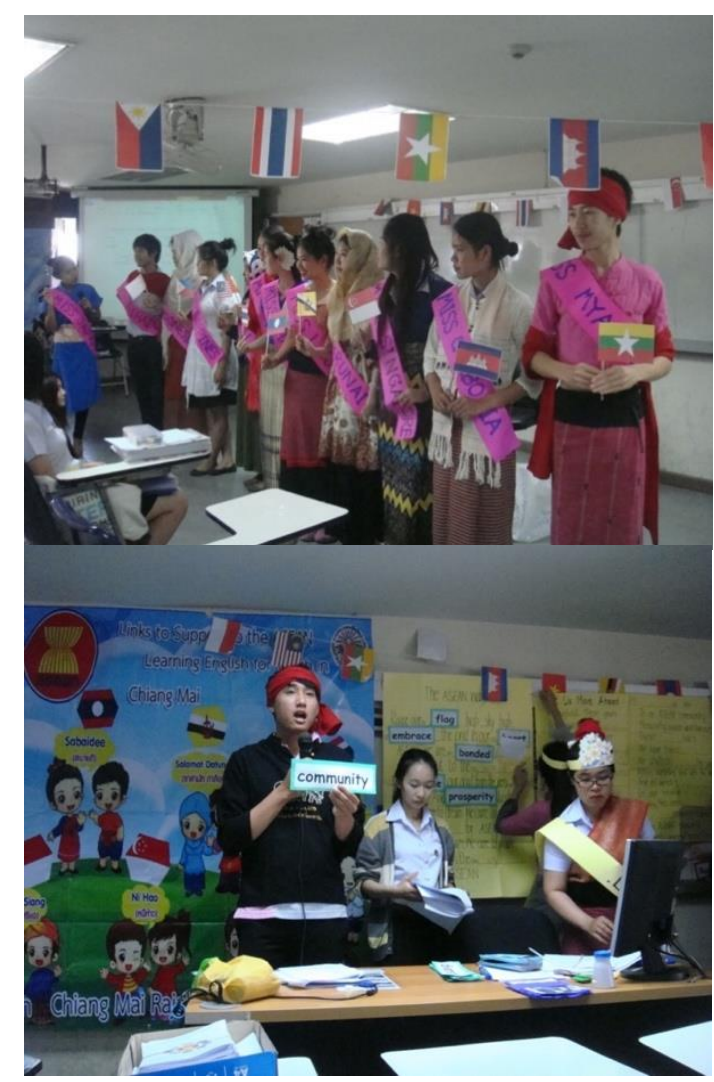

Figure 1. EFL trainee students' ICLT competence: The example of group $1^{\text {st }}$ lesson plan content "Welcome to the ASEAN Community".

As it is illustrated in Figures 1 regarding Unit 1 "Welcome to the ASEAN Community," this was indeed students' first exposure to the cultural lessons and content. This group lesson plan included information about each 10 member countries in the ASEAN community, mainly concerning symbols, greetings, costumes, and money currencies, while using some of 8 steps of a 4MAT approach in the teaching practices (Step 1: Creating Experience, Step 2: Analyzing experience, and Step 3: Integration of reflection into concept) through many interesting activities.

From Figures 2-3 relating to Unit 2 "Travel through the ASEAN Community," pertains to an example of cultural lesson. The lesson plan of these two groups included information about places to eat and to see around the ASEAN community, mainly concerning with ethnic food and national landmarks, while using some of 8 steps of a 4MAT approach (Step 4: Developing theories and concepts) through mind mapping and writing activities. This meant that during the course the trainee students' ICLT competence significantly improved.

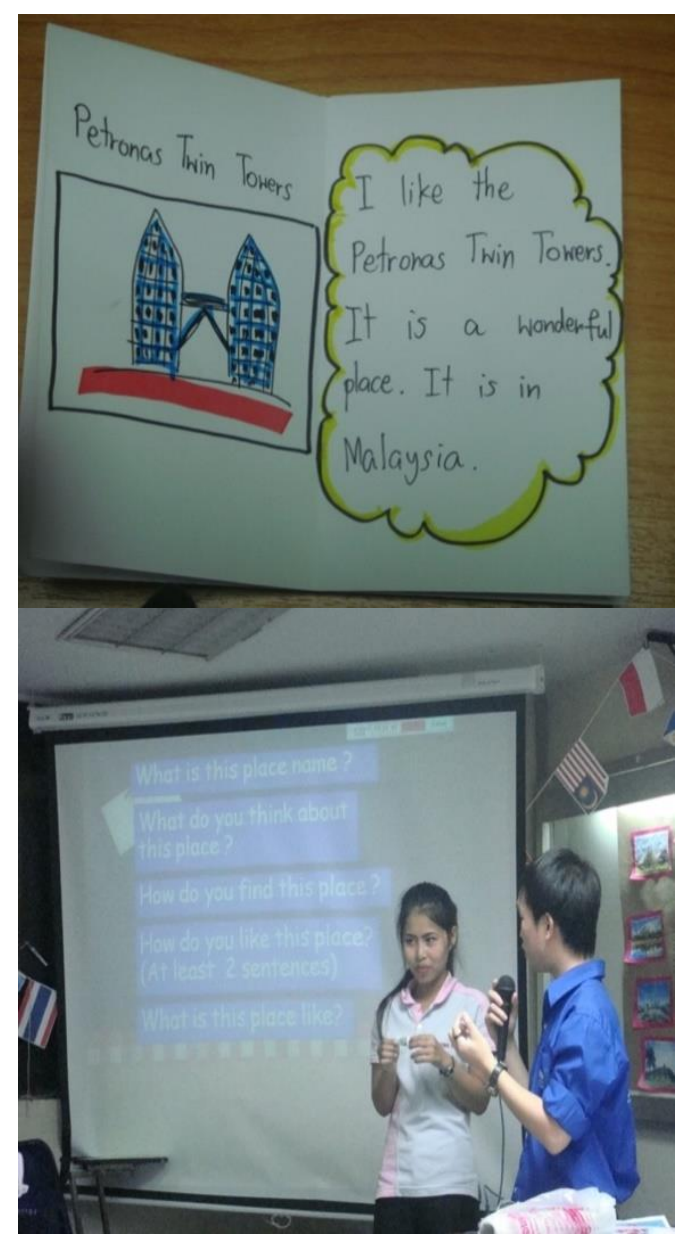

Figure 2. EFL trainee students' ICLT competence:

The example of group $2^{\text {nd }}$ lesson plan content "Travel to see around the ASEAN Community". 


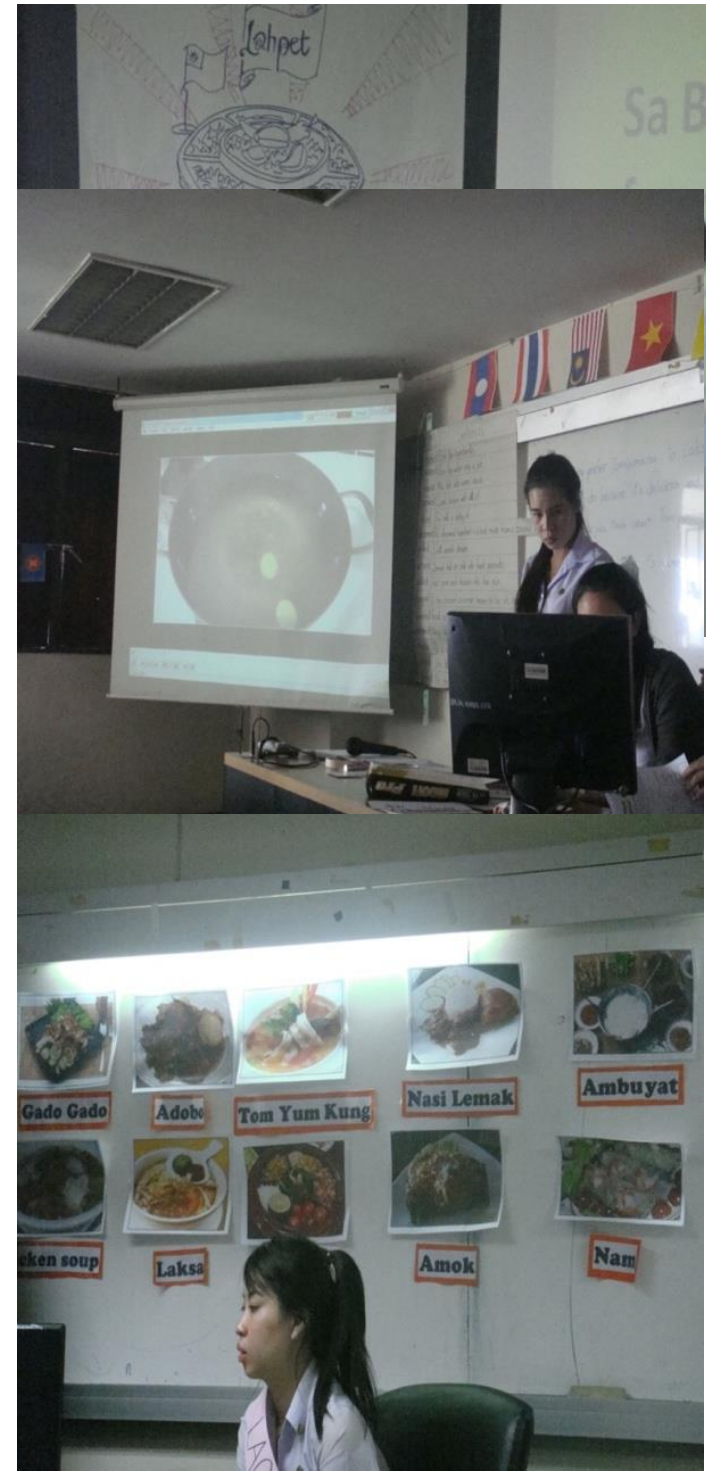

Figure 3. EFL trainee students' ICLT competence: The example of group $3^{\text {rd }}$ lesson plan content "Travel to eat through the ASEAN Community".

Figures 4 pertains to Unit 3 "Cultural Wonders," and is the most relevant cultural lesson content. This group's lesson plan offered information mainly concerning things to do and not to do when traveling through the ASEAN community, and while using some of 8 steps of a 4MAT approach (Step 4: Developing theories and concepts, Step 5 Working on defined concepts and Step 6 Messing around) through various activities. This illustrated that during the course the trainee students' ICLT competence significantly improved.

The successful completion of the activities, of 4 groups in all three units of ASEAN Studies through the 8 - step 4MAT approach illustrates the quality process of the ICLT model. It is said that "To learn it, do it" associated with the ICLT model, which

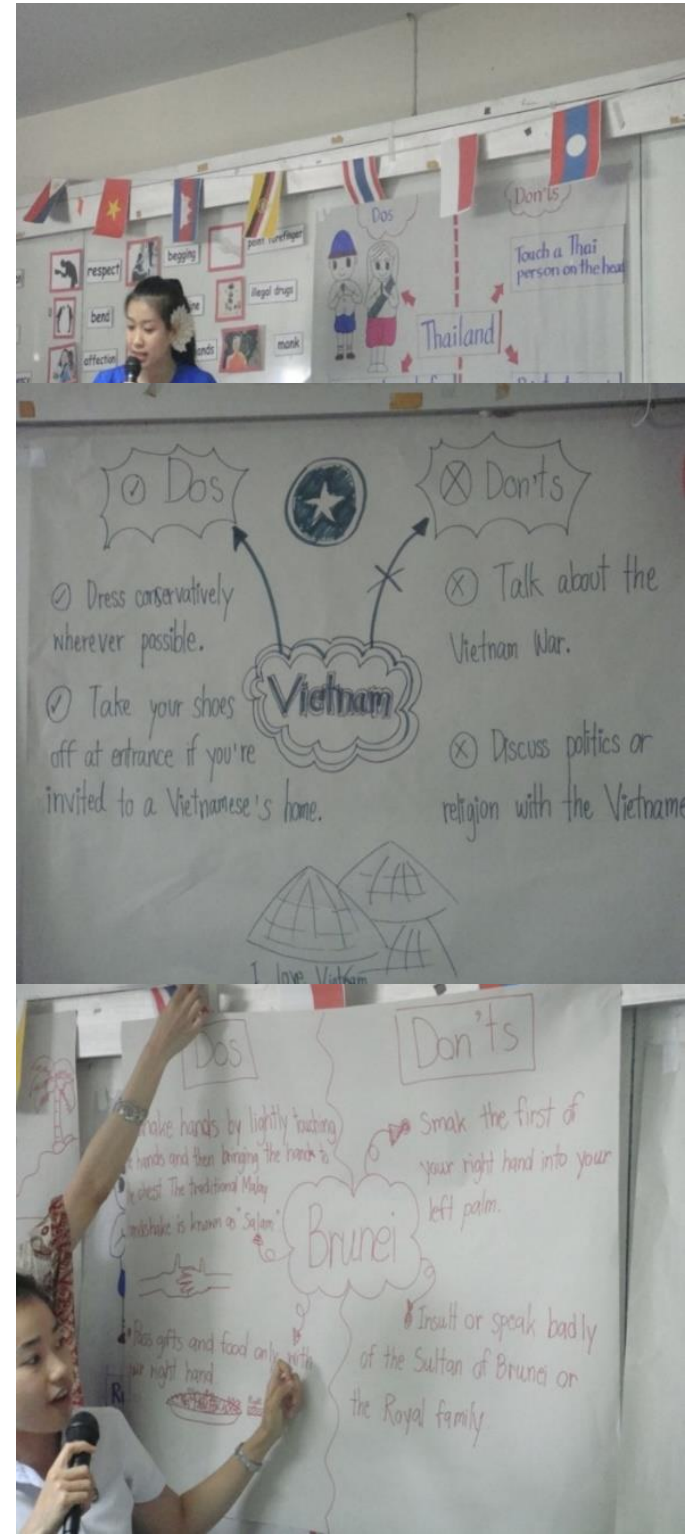

Figure 4. EFL trainee students' ICLT competence: The example of group $4^{\text {th }}$ lesson plan content "Cultural Wonders".

provides learners with real-life situations to practice [14].

The research results of the 4MAT approach in science subjects in North Carolina (USA) indicated that the learning achievements and retention of knowledge of students in government schools in terms of encouraging students' interest in lessons was at high scores level of learning with 0.05 of Standard Deviation (S.D.) [23]. Figure 5 briefly shows how these activities worked for the 62 trainee students. 


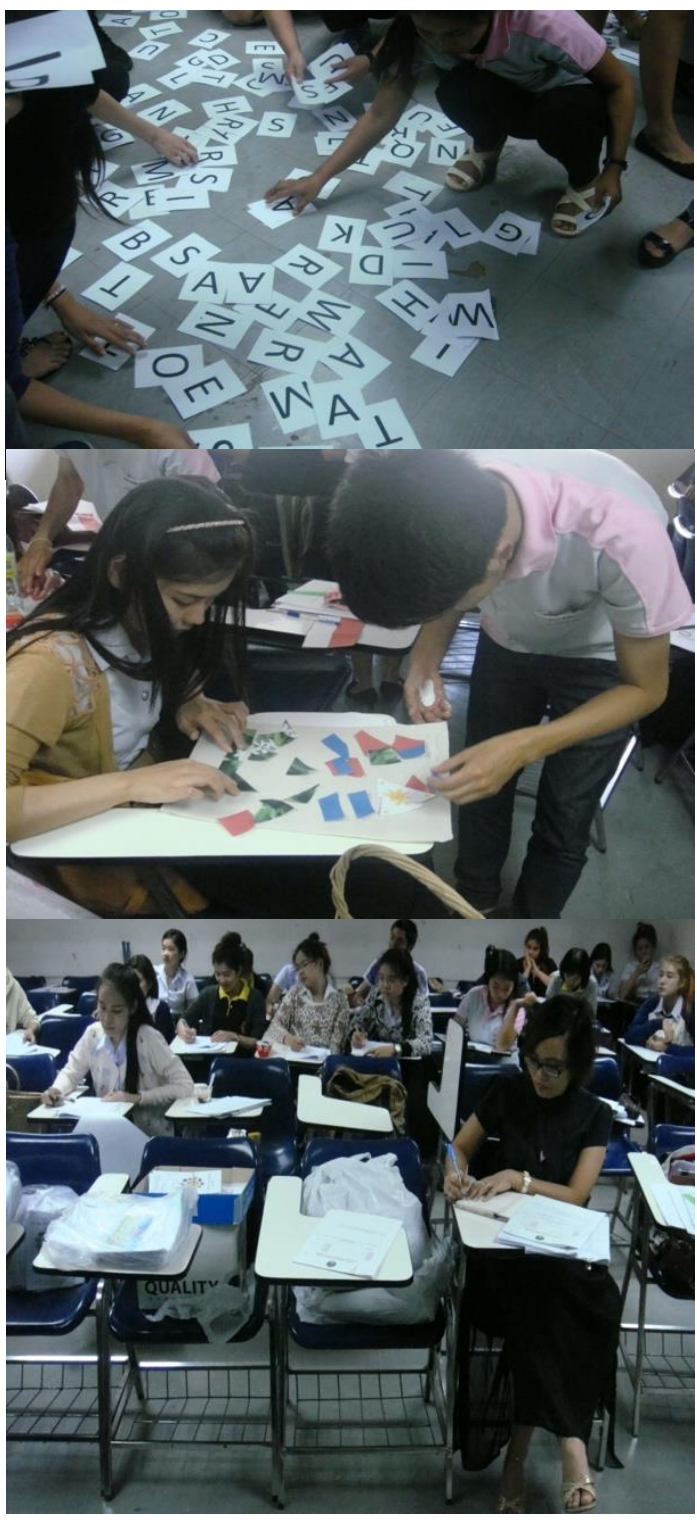

Figure 5. EFL trainee students' ICLT competence: The example of activities successfully done in each unit of ASEAN studies through the 8 steps of 4 MAT approach.

\section{Discussion}

The findings revealed that the EFL trainee students' attitudes towards ICLT were positively high after a ten-week course, as they were aware of ICC and the importance of the ICC, and believed in the important roles of the ICLT. In other words, learners understood what ICC was, what it was for, and how IC was composed. This may be the result of the teacher's strategies in raising awareness through the training sessions, which were a crucial aspect of ICC instruction. The learner's awareness is ultimately one of the necessary conditions for the learning process to take place [19]. These results matched those of previous studies (e.g., [15]; [16]. A study pertaining to a framework to develop ICC and the proficiency of advanced learners of the Arabic language found that the proposed lingua-cultural framework not only improved students' abilities to recognize and produce varieties in the language which was used in Egypt, but also fostered learners' IC abilities (knowledge, attitude, awareness, and skills) [21]. Learners' intercultural communicative competence development reflected by the four pillars (1. Learning to know: cross-cultural knowledge; 2. learning to do: intercultural skills; 3 learning to live together: Intercultural attitudes; and 4. learning to be: intercultural awareness) of education for the twentyfirst century as identified by the International Commission on Education for the Twenty-First Century [6], which was developed as four distinct aims of intercultural education, and which has been incorporated in the guidelines of international education suggested by UNESCO [22].

Additionally, the finding of the highest percentage of teaching score of 98.46 by EFL trainee students' towards ICLT competence were due to a variety of teaching and learning activities during the ICLT model lessons (e.g., warm-up activities, roleplay, discussions, mini-project, child-centered teaching approach and use of the variety of visual aids and materials). These trainee students were engaged in different situations in which ICC was involved with the very clear content and easy to understand guidelines. They understood the meaning, the main components, and the benefits of ICC. Trainee students also learned that strategies were very useful if the approach was the 4MAT method accompanied by components that motivate and involve learners in learning and constructing new knowledge and by using critical thinking through their own experiences. Noticeably, trainee students applied their own practices using some of these approaches; through active participation, and higher order of thinking, improved attitude and motivation for further learning, reflecting the effective learning outcomes. [3].

Group or team teaching in the ICLT practices, by the trainee students, indicated that they had worked in small groups, shared ideas, looked for different data and information, and analyzed and evaluated, and finally synthesized the data, which in return, led them to create very useful lesson plans to teach critical thinking. Additionally, involvement in problem-solving, cooperative learning, simulations, debates, and presenting sessions enhances learners' critical thinking [12].

\section{Conclusion}

Recognizing effectiveness of the developed instruction may prove to be of significant value to trainers, educators, administrators, and particularly practitioners, including trainee students. Therefore, 
trainees must get exposed to diverse teaching methods and activities through multiple interpretations and perspectives of a situation. In this study and through practice, trainee students gained experiences in a number of areas, namely: in exploring opinions, becoming engaged in discussions with an open mind, handling conflict, and negotiating agreements, accepting compromises, as well as in analyzing and synthesizing information to make sound decisions and to draw conclusions. The explanations were consistent with the concepts of critical thinking [8]. Relatively, when using active learning, learners are engaged in more activities than just listening [1]. Practice is critical to the development of thinking skills and in the integration of teaching a particular subject matter, and ICC provides a greater likelihood for transferring of knowledge and for further development due to more significant opportunities for practice in thinking and education through diverse situations [11].

Therefore, in order to foster the implementation of ICLT in the Thai context and other similar circumstances, especially for EFL learners and trainee students, there should be a shift from the current teaching method to an intercultural language approach. First, the trainee students should be assisted to gradually acknowledge the importance of integrating intercultural content into standard English language classes. Moreover, they should be encouraged and motivated to be autonomous learners, and based on the acquisition process of ICC, a matter of life-long learning. Interactions between trainee students and their trainer are essential for promoting learning success. The interactions are characterized by providing trainee students with frequent and engaging learning activities, motivating and supporting them to think meaningful challenges, facilitating language barriers, and finally recognizing their needs for a sense of autonomy and an active role in learning. Student-to student and student-to-instructor interactions are consistent with improvement in the ability to think critically. [4].

All in all, the teaching materials are chosen for ICLT should promote learners' ICC, and the content of the learning materials should be authentic, up-todate, informative, and appropriate for learner's age group and interest. (P66) [17]. Appropriate instruction is extremely important in fostering trainee students' thinking skills and in developing their abilities in teaching language to students. To infuse trainee students with critical thinking skills and critical thinking teaching abilities is to think of them not as receivers of information, but as the users of information. Any learning instruction or environment that actively engages trainee students in the application of knowledge will promote their thinking skills and enhance their abilities in teaching intercultural contents to students in accordance with that who expressed these descriptions and illustrations which are congruent with those of critical thinking [10].

\section{Acknowledgement}

The author's acknowledgments would go extensively to all anonymous participants for their willingness to participate in this project, and the financial support of Chiang Mai Rajabhat University and the collaboration of the National Research Council of Thailand (NRCT) and the Thailand Research Fund (TRF). Without their willingness, help, and support, this project would never get completed.

\section{References}

[1] Bonwell, C. C., and Eison, J.A. Active learning: Creating excitement in the classroom. Washington, DC: The George Washington University, 1991.

[2] Byram, M. Teaching and Assessing Intercultural Communicative Competence. Philadelphia, PA: Multiling ual Matters, 1997.

[3] Chapman, B. S. Emphasizing concepts and reasoning skills in introductory college molecular cell biology. International Journal of Science Education, 22 (11), 2001, pp. 1157-1176.

[4] Cooper, J. Cooperative learning and critical thinking. Teaching of Psychology, 22 (1), 1995, pp. 7-9.

[5] Deardorff, D. K. "Identification and Assessment of Intercultural Competence as Student Outcome of Internationalization", Journal of Studies in Intercultural Education, 2006, 10, pp. 241-266.

[6] Delors, J. Learning, the Treasure within: Report to UNESCO of the International Commission on Education for the Twenty-first Century. Paris: UNESCO Pub., 1996.

[7] Fantini, A. E. "A Central Concern: Developing Intercultural Competence". SIT Occasional Papers (Addressing Intercultural Education, Training and Service), 2000, 1, pp. 25-42.

[8] Gomez, F. Jr. "Education as if people matter: A call for critical thinking and humanistic education", http://www. cavehill.uwi.edu/BNCCde/belize/conference/papers/11-082017/gomez.html. [Accessed: 11-August-2017]

[9] Gonen, S. I. K., and Saglam, S. "Teaching Culture in the FL Classroom: Teachers' Perspectives”, IJGE:

[10] Greetsen, H. R. Rethinking thinking about higherlevel thinking. Teaching Sociology, 31 (1), 2003, pp. 1-19

[11] Halpern, D. F. "Teaching critical thinking for transfer across domains: Dispositions, skills, structure training, and 
[12] Howe, R. W., Warren, C. R. Teaching critical thinking through environmental education. Columbus, $\mathrm{OH}$ : Clearinghouse for Science, Mathematics, and Environmental Education, 1989.

[13] McCarthy, B. A Table of four Learners: 4MAT's learning styles. Educational Leadership, 1997, March, pp. 46-51.

[14] Morrow, K. Communication in the Classroom: Applications and Methods for a Communicative Classroom. London: Longman, 1981.

[15] O'Neil, J. E. Intercultural Competence Development: Implementing International Virtual Elementary Classroom Activities into Public Schools in the U.S. and Korea. Doctoral dissertation. VA: University of Virginia, 2008.

[16] Ottoson, K. J. "Classroom Development of Intercultural Competence. In N. Sonda, and A. Krause (Eds.)". JALTI Conference Proceedings, 2013, pp. 119128, http://www.jalt-publications.org/proceedings/issues/ 01-08-2014 [Accessed: 01-August-2014]

[17] Promwatcharanon, K. The Integration of 4MAT Approach with ASEAN Social and Cultural Links: the Development of an Instructional Model to Enhance Youth's Intercultural Communicative Competence and Attitudes. Journal of English Studies, 12 (1), 2017, pp. 3869.

[18] Samovar, L. A., Porter, R. E., and McDaniel, E. R. Intercultural Communication: A Reader $\left(13^{\text {th }}\right.$ ed.). Boston, MA: Wadsworth Cengage Learning, 2012.

[19] Schmidt R. Consciousness and Foreign Language Learning: A Tutorial on the Role of Attention and Awareness in Learning. In R. Schmidt (ED.), Attention and Awareness in Foreign Language Learning. Honolulu, HI: University of Hawaii, Second Language Teaching and Curriculum Center, 1995, pp. 1-63.

[20] Sercu, L. Teaching Foreign Languages in an Intercultural World. In M. Byram, and A. Phipps (Eds.), Foreign Language Teachers and Intercultural Competence. Buffalo: Multilingual Matters, 2005, pp. 1-18.

[21] Shoman, M. M. Developing Intercultural Communicative Competence and Proficiency of Advanced Arabic Learners: A Proposed Framework. Unpublished master's dissertation. The American University, United State, 2011.

[22] United Nation Educational, Scientific, and Cultural Organization (UNESCO). UNESCO Guidelines on International Education. Paris: UNESCO Headquarters, 2006.

[23] Willkerson, R. M, and White K, P. Effects of the 4 MAT System of Instruction on Students' Achievement, Retention, and Attitudes. The Elementary School Journal, 88(4), 1998, pp. 357-368. 